\title{
Primary Intra-Articular Synovial Sarcoma of the Knee: A Report of Two Cases and Review of the Literature
}

\author{
Justin E Hellwinkel, Ryan P Farmer*, Austin Heare, Joshua Smith, Nathan Donaldson, \\ Michael Fadell and Travis Heare
}

Children's Hospital Colorado, Aurora, USA

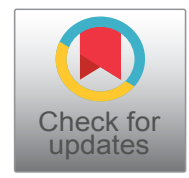

*Corresponding author: Ryan P Farmer, MD, Children's Hospital Colorado, 13123 E 16th Ave, Aurora, CO 80045, USA, Tel: 303-884-5143, E-mail: ryan.farmer@ucdenver.edu

\begin{abstract}
Case: We highlight two cases of primary intra-articular lesions with imaging consistent with Pigmented Villonodular Synovitis (PVNS) and synovial chondromatosis. These benign neoplasms are typically treated with arthroscopic synovectomy. However fluid insufflation of the knee joint in the setting of intra-articular malignancies can dramatically change treatment options.

Conclusion: Isolated intra-articular masses in the knee should have careful consideration of the differential diagnosis. These cases highlight the importance of adhering to diagnostic and treatment algorithms for the management of soft tissue masses to avoid potentially catastrophic complications. These cases support the consensus that arthroscopic excisional biopsy is not indicated as the primary procedure for an intra-articular soft tissue mass of unknown etiology.
\end{abstract}

\section{Keywords}

Synovial sarcoma, Intra-articular, Knee, Pigmented villonodular synovitis, Synovial chondromatosis, Arthroscopic, Arthroscopy, Biopsy

\section{Introduction}

Synovial sarcoma is a misleading term initially coined in reference to its pathological appearance that mimics synovium in its early stage of development. In reality, Synovial Sarcoma (SS) is a rare malignant neoplasm, which accounts for only 2.5 - $10 \%$ of all soft-tissue sarcomas $[1,2]$. Peak incidence of SS occurs in the third decade of life, and $30 \%$ of cases occur in children and adolescents younger than 20 years of age. Although synovial sarcoma is more common in adults, it remains the sec- ond most common soft-tissue sarcoma in children and adolescents, after rhabdomyosarcoma [3].

Approximately $80 \%$ of primary SS arise in the extremities, most commonly in the para-articular regions, the knee being the most common site. However, true intra-articular origin is extremely rare, accounting for less than $5 \%$ of cases [4-7]. From an oncological standpoint, SS is generally regarded as a high-grade sarcoma characterized by slow tumor growth, and a propensity to invade local structures. These tumors have a $30-60 \%$ incidence of metastases, which may sometimes develop more than 5 years after the initial diagnosis [8-13].

Synovial sarcomas are often diagnosed after surgical excision of misdiagnosed benign lesions. Excision of these masses have shown to leave residual tumor in up to $82 \%$ of cases [14]. Low-risk synovial sarcomas in pediatric and adolescent patients treated with surgical excision alone show $72 \%$ - $90 \%$ event-free survival at 5 years $[15,16]$. Intermediate and high risk tumors treated with surgery alone have a more variable 5 -year survival between $36 \%-76 \%$, which raises the need for adjuvant treatment [17]. Synovial sarcoma is relatively chemosensitive within the class of soft tissue sarcomas. A study of 313 cases of synovial sarcomas showed a $27.8 \%$ response to chemotherapy compared to $18.8 \%$ of other soft tissue sarcomas [18]. Ifosfamide and doxorubicin are the most efficacious chemotherapies for this tumor and have shown to result in $60 \%$ survival at 5 years in the absence of surgical excision. Chemotherapy combined with surgical excision and radiation therapy increases overall survival to $80-95 \%$ after 3 years $[19,20]$. 


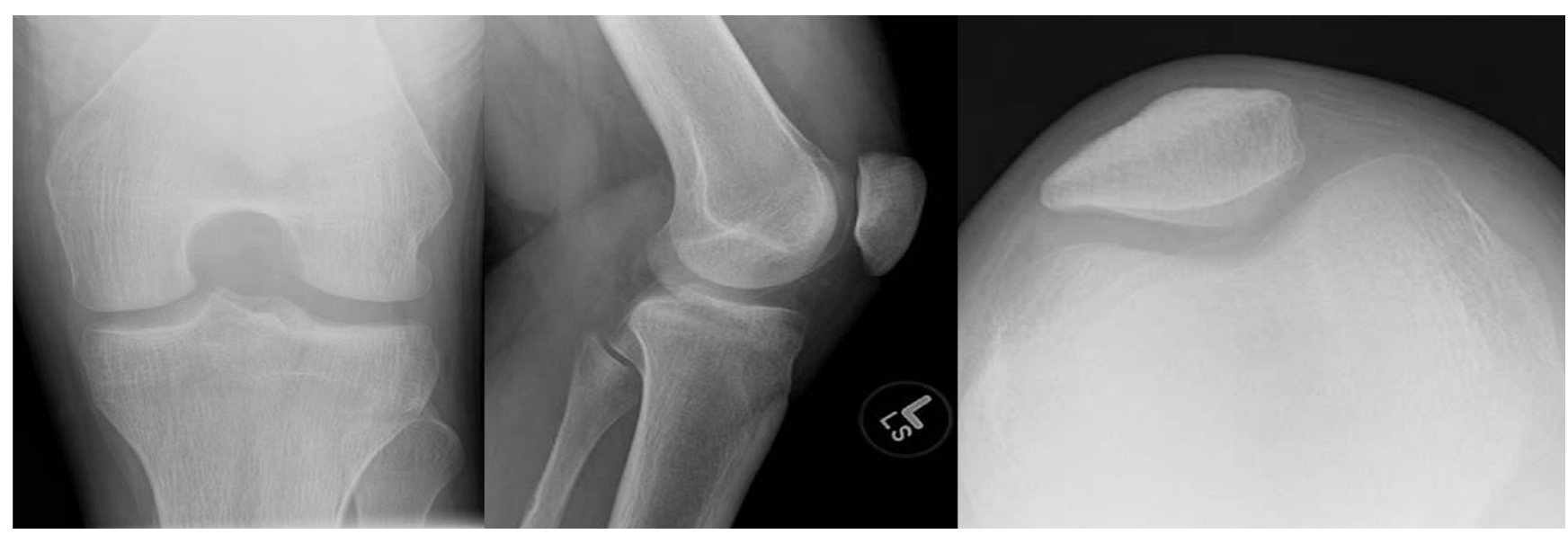

Figure 1: Sunrise, AP and Lateral views of the left knee show no abnormality.

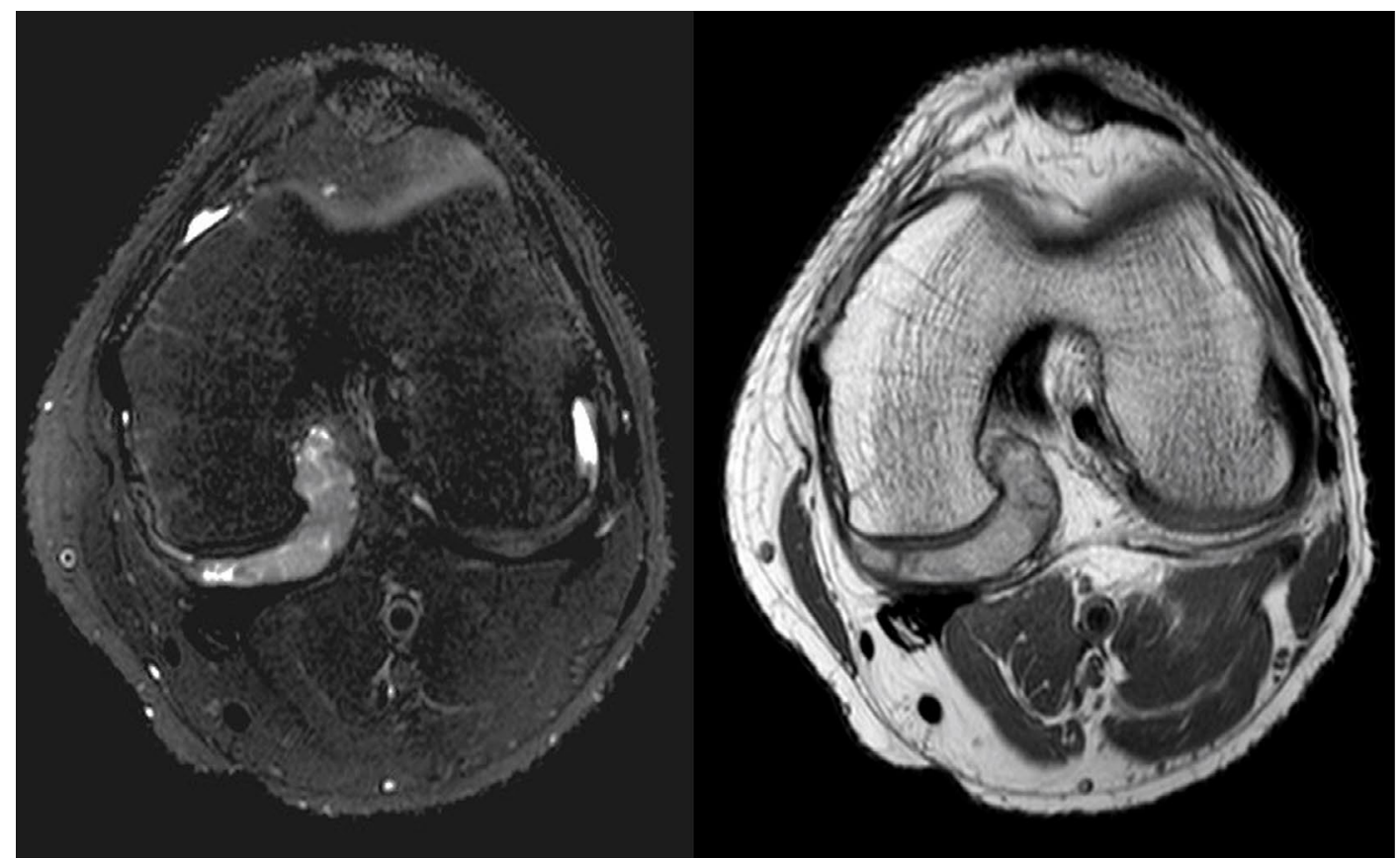

Figure 2: Axial T2 fat saturated and Proton Density MRI images of the left knee.

The radiographic features of SS have been described by multiple authors, however, there are no definitive imaging characteristics that are diagnostic for SS [2124]. In fact, in the few cases of intra-articular SS that have been reported, the majority were clinically diagnosed as common benign lesions such as synovitis, synovial chondromatosis, and Pigmented Villonodular Synovitis (PVNS) [11]. We present two cases of primary intra-articular SS of the knee, along with a brief review of best-practices in diagnosis and management of intra-articular lesions of uncertain etiology.

\section{Case 1}

A 17-year-old male presented to the orthopaedics clinic approximately one month after a hyperextension injury to his left knee while walking down stairs. He was originally seen in the emergency department and presented to orthopaedics after failure of conservative management. Physical exam revealed focal tenderness along the lateral and posterior joint line with a small pal- pable effusion. A positive Apley's test was elicited and plain films were read as normal (Figure 1). Lateral meniscal tear with possible posterior capsular sprain was suspected and the patient was sent for an MRI of the left knee (Figure 2, Figure 3 and Figure 4 demonstrate a lobulated mass, with low $\mathrm{T} 1$ and heterogeneous $\mathrm{T} 2$ signal measuring up to $2.7 \mathrm{~cm}$ AP by $3.0 \mathrm{~cm}$ craniocaudal by $3.7 \mathrm{~cm}$ transverse dimensions within the intercondylar notch, just superficial to the mid posterior cruciate ligament and extending into the medial posterior recess. The mass shows mild, heterogeneous enhancement and minimal scattered blooming artifact consistent with calcium or hemosiderin deposition).

The primary differential considerations on initial MR images included PVNS of the focal, rather than diffuse, type, or less likely a complicated pericruciate ganglion cyst. However, after follow-up MRI with gradient echo and post-contrast images, most likely diagnosis was focal PVNS, or less likely, partially calcified synovial chondromatosis. One month later, the patient underwent 


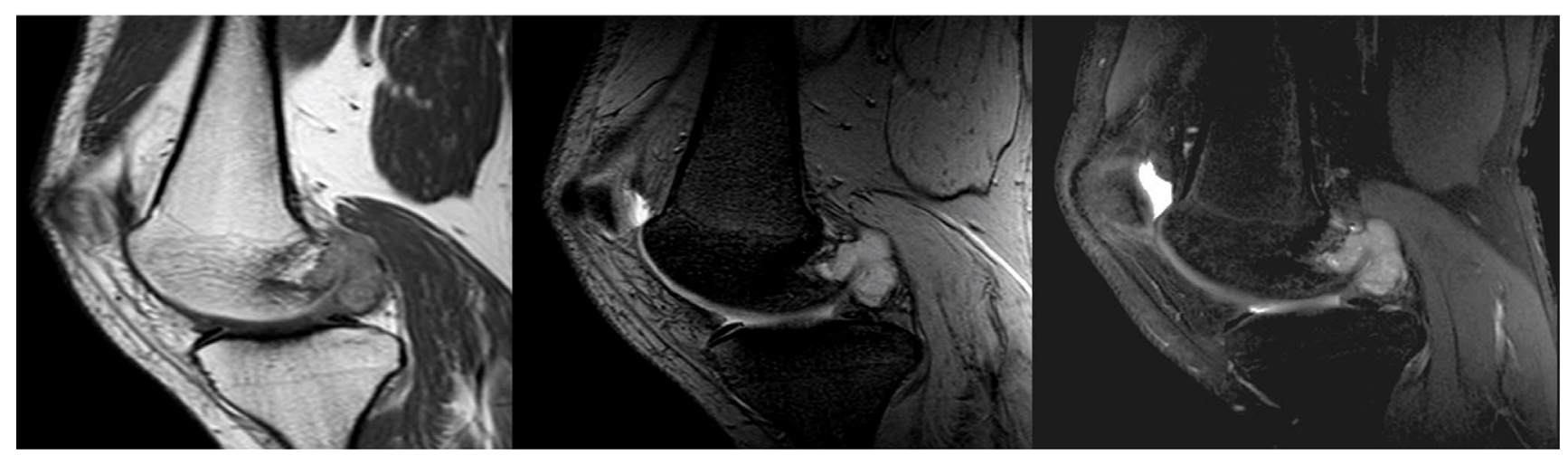

Figure 3: Sagittal T1 post-contrast, Gradient Echo, and T2 Fat-Saturated MRI images of the left knee.

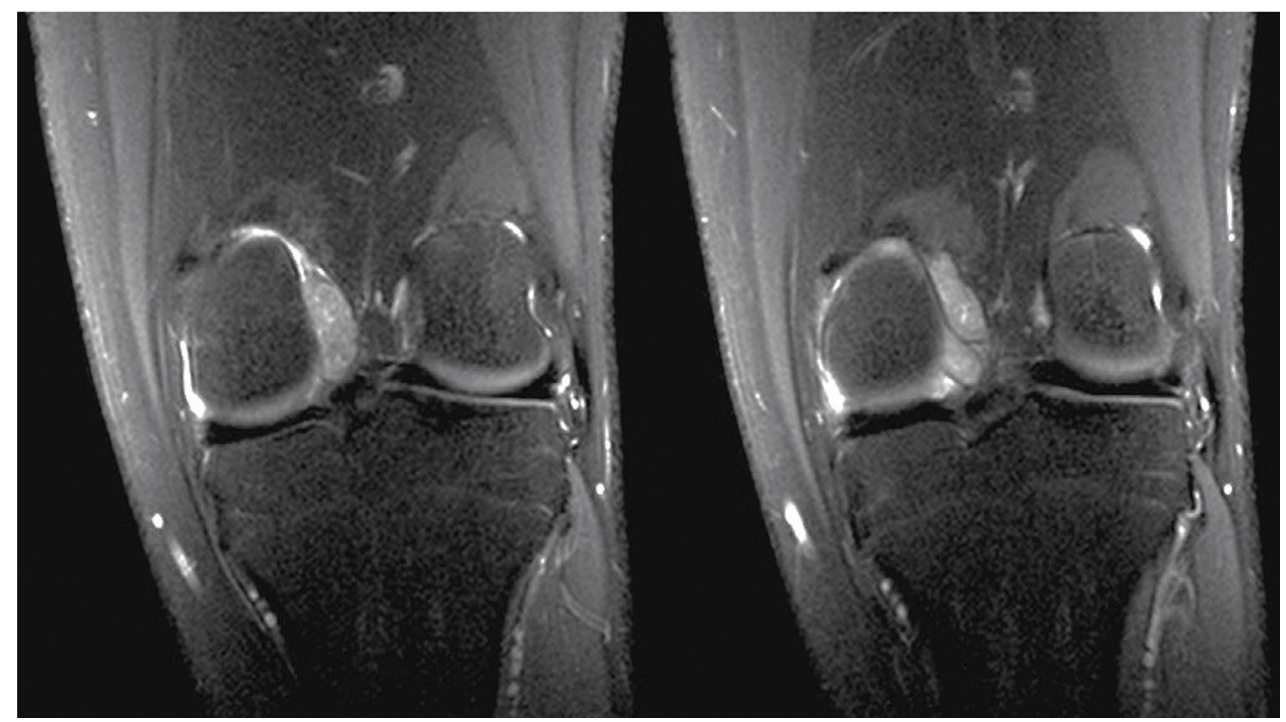

Figure 4: Coronal Proton Density fat saturated MRI images of the left knee.

A

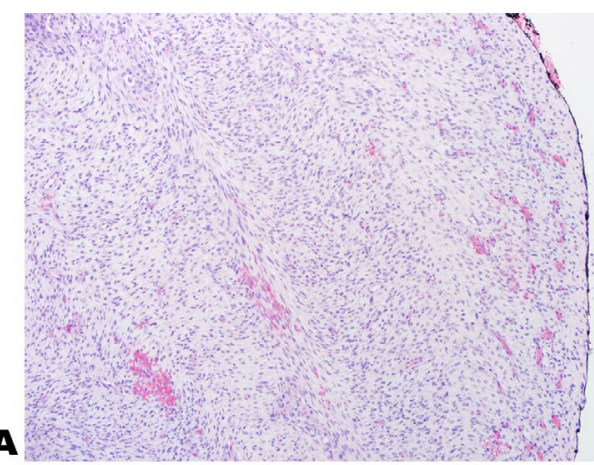

C

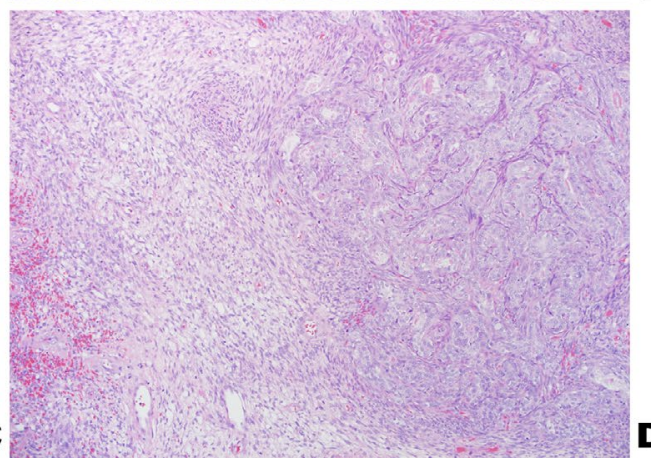

B
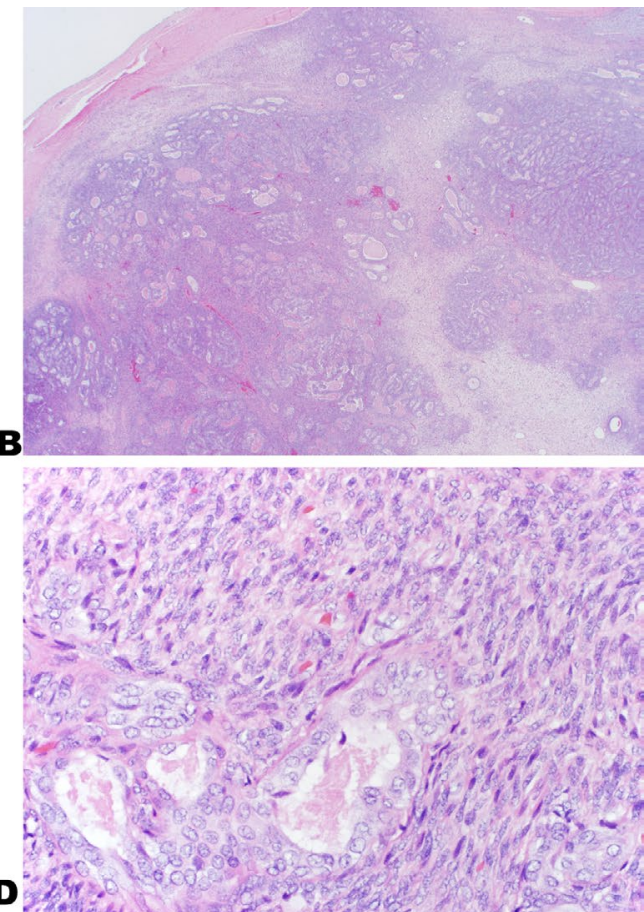

Figure 5: Images of the tumor stained with H\&E with inked margins at 10x (A); H\&E 2x (B); H\&E 10x (C) and H\&E 40x (D). Permanent sections show well-defined nodules of biphasic tumor cells consisting of dense spindle cells with overlapping nuclei arranged in fascicles and gland-forming epithelioid cells with vesicular nuclei and amphophilic cytoplasm. Hemosiderin-laden macrophages were present adjacent to foci of hemorrhage. Tumor cells were identified near the inked margins. The tumor cells did not exhibit high mitotic activity. 

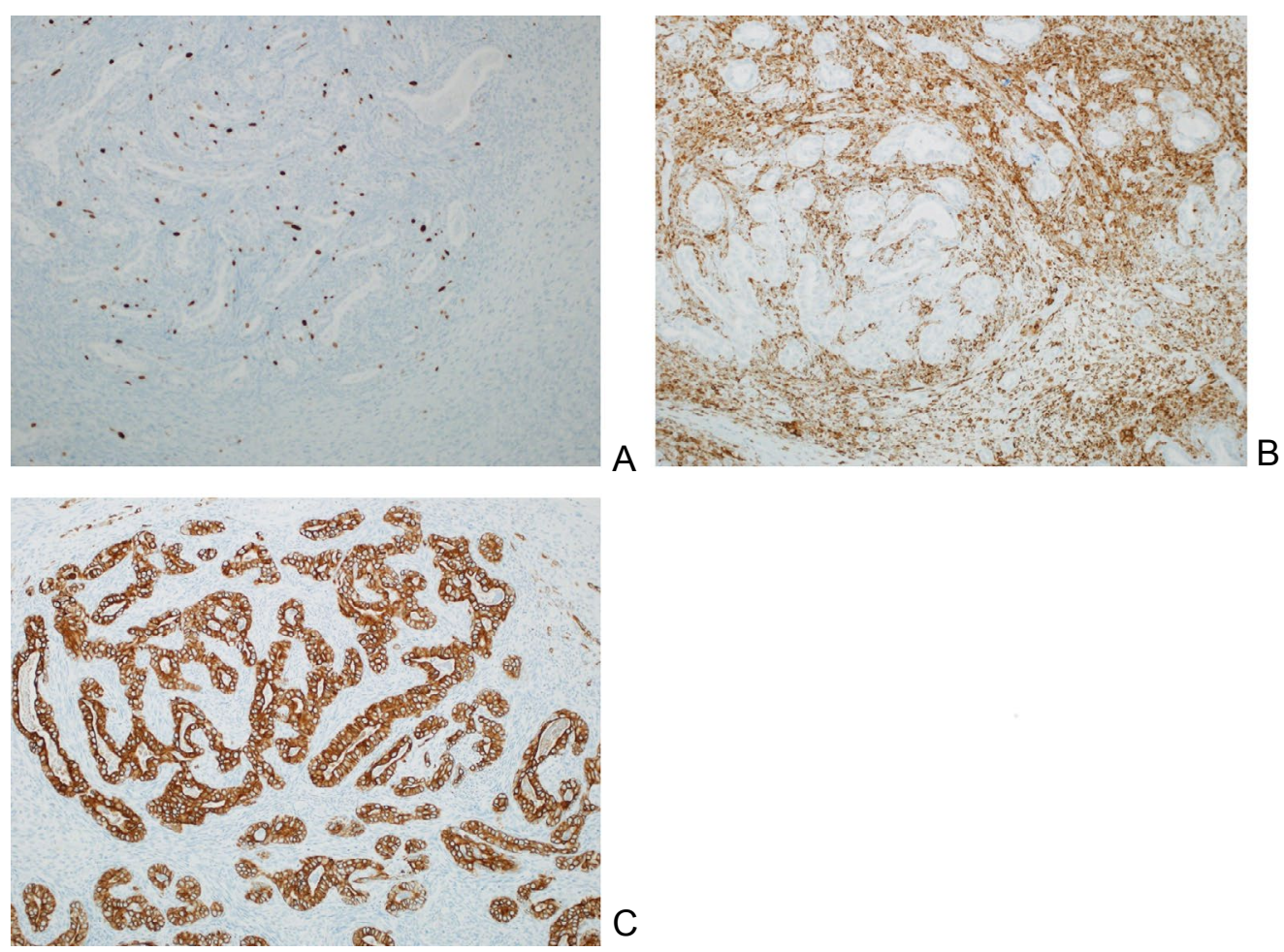

Figure 6: Images of different pathology stains including MIB (A); BCL-2 (B); Pan cytokeratin (C).

The glandular cells are diffusely were strongly positive for pan cytokeratin immunostain; occasional spindled cell positivity was also noted. A BCL-2 immunostain was strongly and diffusely positive in the cytoplasm of the spindle cell component with focal positivity in the glandular component. A CD99 immunostain showed background staining. CD68 immunostains highlighted scattered macrophages. A CD34 immunostain shows scattered vessels.

an open posterior excisional biopsy for presumed focal PVNS.

Intraoperative frozen section was reported to show prominent synovial-lined villous structures with xanthomatous cells, rare giant cells, inflammatory cells, and hemosiderin, consistent with a diagnosis of PVNS. However, microscopic exam of permanent sections was reported to be discordant with the frozen section diagnosis (Figure 5 and Figure 6). Fluorescent In Situ Hybridization (FISH) studies of the specimen were positive for $t(X ; 18)$ SYT gene rearrangement, confirming a diagnosis of synovial sarcoma. Margins on the resected specimen were clear but tumor cells were present within millimeters of the resected capsular margin.

\section{Staging, treatment, and follow-up}

Staging of the tumor with PET/CT and non-contrast CT of the chest were undertaken and showed no evidence of metastatic disease, although a focus of increased FDG uptake was noted in the posterior left knee at the site of the known primary tumor, likely representing post-operative inflammatory change.

2 months later, the patient was taken back to the operating suite for arthrotomy and re-excision of the prior capsular margin. Final pathology at this time demonstrated no evidence of residual neoplasm with clean margins. The patient underwent postoperative radiation therapy. No chemotherapy was indicated, as the tumor was less than $5 \mathrm{~cm}$.
The patient was allowed to weight-bear following surgery with the avoidance of impact type activities until his 6 month post-operative visit. At the 2 year post-operative follow up visit he was doing well and had no evidence of local recurrence or metastatic disease on serial MRI of the left knee and chest CT scans at 3 month intervals.

\section{Case 2}

A 14-year-old boy presented to an orthopaedic surgeon with several months of knee pain with no known inciting event. The pain had been gradually worsening, especially with deep knee flexion. He denied any instability or mechanical symptoms. The patient's symptoms remained refractory to conservative management so plain films of the knee were obtained (Figure 7).

These images prompted the treating surgeon to order an MRI without contrast to further characterize the mass (Figure 8 and Figure 9). The differential diagnosis following MRI included synovial chondromatosis, atypical pigmented villonodular synovitis, or a large chondral loose body.

Following this, the treating surgeon suggested arthroscopic excisional biopsy, which was done the following month. A standard arthroscopic approach was used with the addition of an accessory posteromedial portal to visualize the mass. Diagnostic arthroscopy was normal except for the posteromedial knee mass, which had a paste-like consistency. Three biopsy specimens 
were obtained and the remainder of the lesion was removed with an arthroscopic shaver.

Pathology diagnosis was received by the treating institution and subsequently sent out to two different outside facilities for confirmation. All pathologists involved agreed with the diagnosis of synovial sarcoma. This was further confirmed with genetic analysis. CT chest and repeat $M R I$ with contrast of the right knee showed no evidence or metastasis or residual tumor. The patient was subsequently referred to a multidisciplinary sarcoma team for further management.

\section{Staging, treatment, and follow-up}

Three months following the initial arthroscopic resection the patient was taken to the OR for sentinel node biopsy from the right inguinal region. The patient

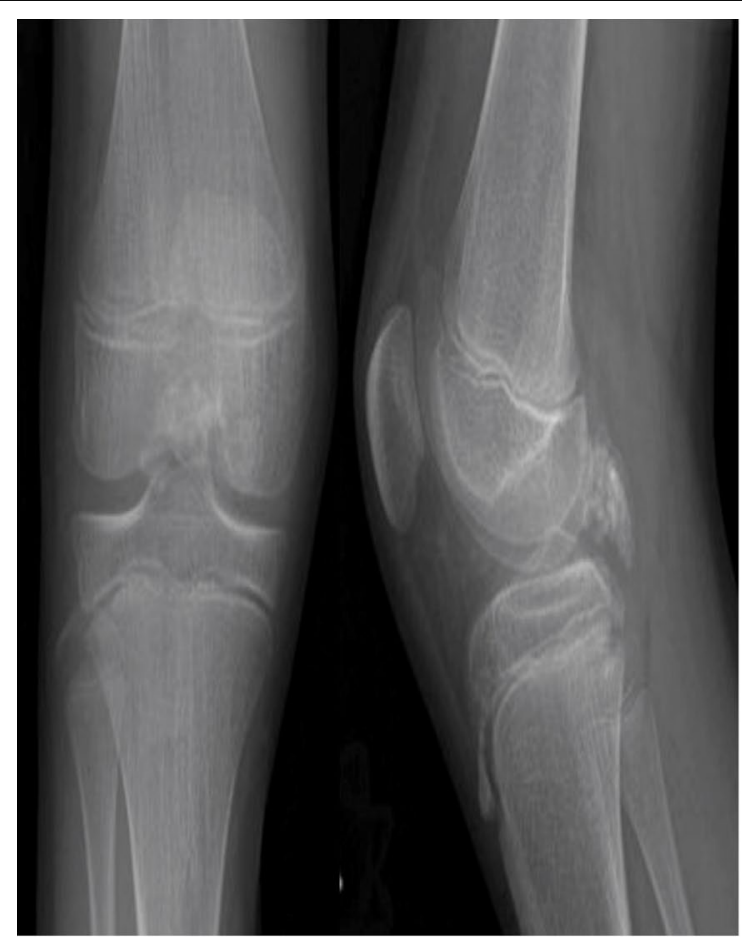

Figure 7: AP and Lateral views of the right knee show calcified mass in posterior midline knee. was first seen at an outside institution where a biopsy of the lesion was performed, and diagnosis was made. The patient was offered above the knee amputation as surgical treatment at this facility. They decided to seek a second opinion from our institution for alternative treatment options which led to a delay in definitive management of his lesion. At our facility the sentinel node biopsy was performed. Subsequent pathology and PET scan revealed no evidence of metastatic disease. Treatment options were discussed with the patient, including above-knee amputation, or extra-articular wide resection with rotationplasty reconstruction. Because of the contamination of the joint space and fluid extravasation into the surrounding tissues with the previous arthroscopy, it was felt that repeat intra-articular resection and radiation therapy would potentially yield less favorable outcomes for this patient. The patient and his family elected to proceed with extra-articular wide resection and rotationplasty reconstruction. This procedure was performed without complication and with clean final margins.

Post-operative rehabilitation protocol was to begin use of an ischial bearing prosthetic and formal physiotherapy at the 8 week post-operative visit. At the 12 week post-operative visit his prosthetic was cut-down and refitted to allow for limb-bearing and he was instructed to work towards a return to full function.

At a 1 year post-operative visit there was no evidence of local recurrence or metastatic disease on surveillance $\mathrm{MRI}$ and chest CT scans.

\section{Discussion}

A review of the literature reveals only 22 reported cases of primary, intra-articular synovial sarcoma including our patients, and highlights just how rare this condition remains. The knee is the most common reported site of primary intra-articular SS with 16 total cases. The suprapatellar or infrapatellar fossa were involved in 6 patients, and the posterolateral compartment in 1 . The

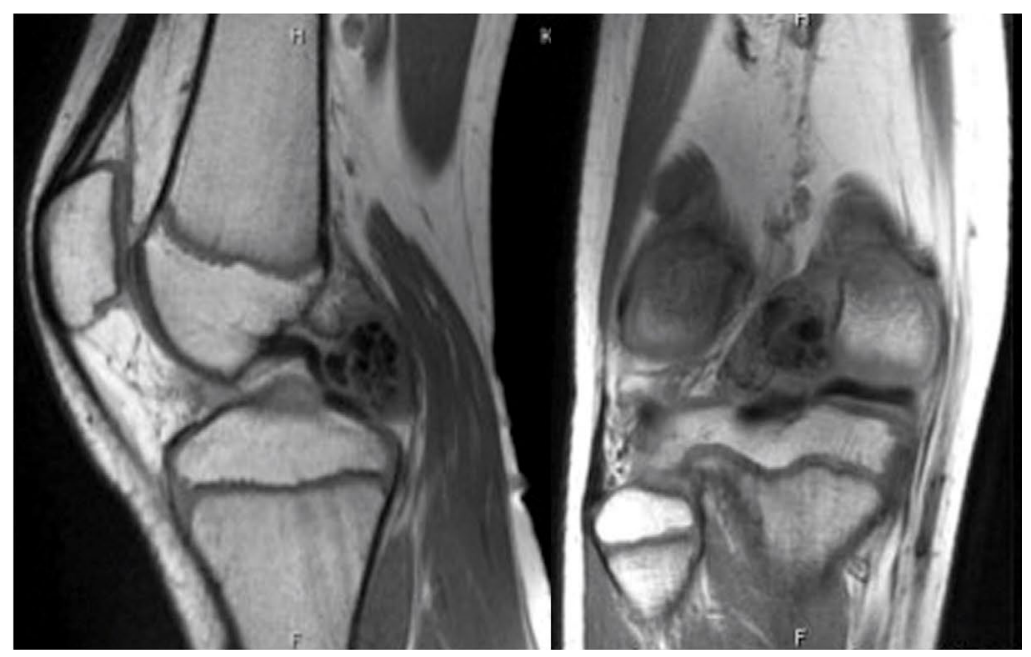

Figure 8: Coronal and sagittal T1 MRI images of right knee. 


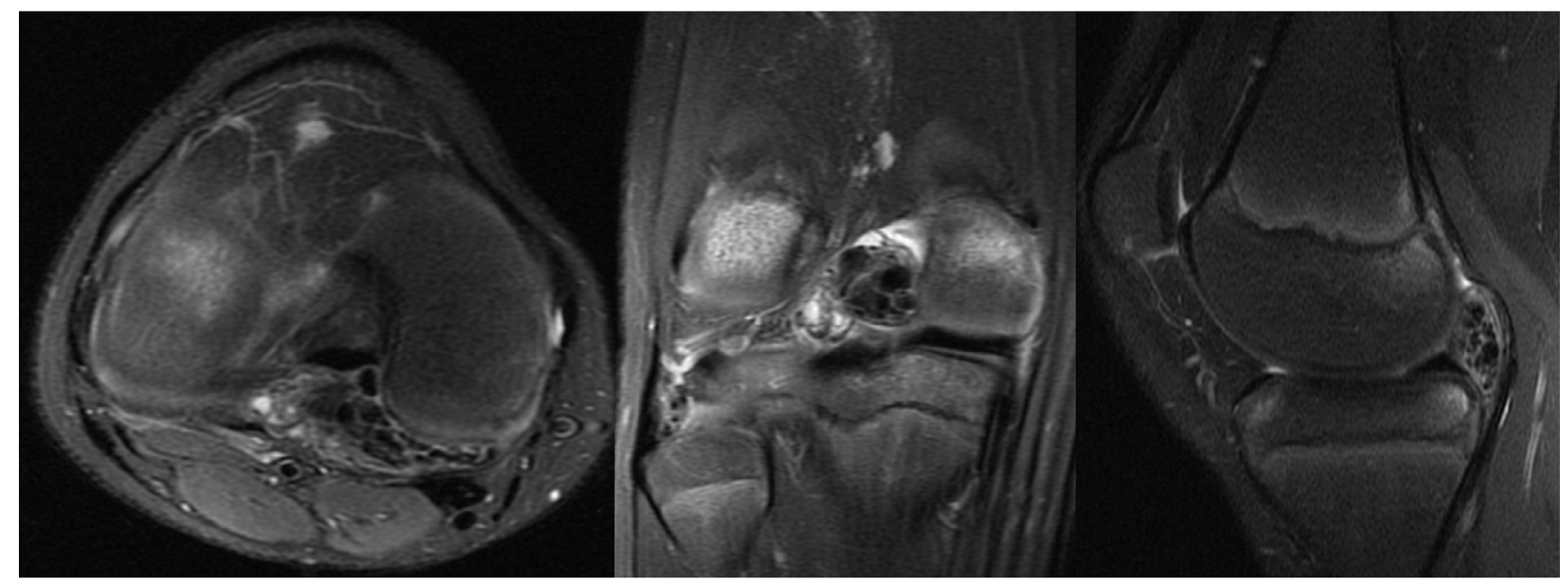

Figure 9: Axial, coronal, and sagittal T2 fat saturated images of right knee.

The MRI shows a $3.9 \times 1.6 \times 2.9$ low T1 and low T2 weighted mass in the posterior joint space that appeared intimately associated with the meniscofemoral ligament of Wrisberg.

intercondylar notch was involved in 3 patients, including ours, and the remaining 6 were undisclosed. Currently, 9 cases of intra-articular SS have been reported with specific MRI findings [25-36].

Plain radiographs appear normal in approximately $50 \%$ of synovial sarcomas and are especially common in smaller lesions. Calcifications can be seen in approximately $30 \%$ of these tumors on plain radiographs [32]. As with other soft tissue tumors, MRI is the imaging study of choice for evaluating intra-articular SS. Tumor size, regional invasion, as well as involvement of adjacent anatomical structures may be visualized on MRI and aid in surgical planning. However, distinguishing between benign and malignant neoplasms is often challenging. Classic MRI findings in SS include: a "bowl-of-grapes" appearance, areas of hyper-, iso-, and hypointensity on T2 sequence known as triple signal intensity; fluid-fluid levels; and multilobulated appearance with intervening septa [21-24,37]. Unfortunately, these findings only yield a high specificity in tumors $>5 \mathrm{~cm}$. Tumors $<5 \mathrm{~cm}$ may demonstrate homogenous signal intensity with well-circumscribed margins, making accurate diagnosis more difficult [38].

Cases 1 and 2 illustrate how these malignant neoplasms can masquerade as benign processes and advanced imaging can further perpetuate this. Initially, these cases were mistaken for benign lesions on imaging studies and even on intraoperative frozen section analysis in Case 1. In fact, mistaking this sarcoma for a benign entity has happened with nearly every reported case of intra-articular SS in the current literature [11,2534]. The most recent case report from Freidman, et al. in 2013, demonstrated failure to consider malignancy in a 26-year-old man with a $2.7 \mathrm{~cm}$ intra-articular knee mass that led to a misdiagnosis of PVNS and subsequent arthroscopic resection as in Case 2 presented here-in [11]. After pathologic diagnosis in both these cases, the risk of intra-articular contamination and/or residual tumor set the stage for a much more invasive procedure than may originally have been offered; above-knee amputation or rotationplasty, versus wide resection and radiation therapy [11]. It is presumed that prolonged time between biopsy and definitive surgery as seen in Case 2 would result in poorer outcomes due to growth of cancer cells. No difference in local recurrence or mortality has been seen after waiting up to two months between surgeries. However, definitive treatment to remove the tumor should be done as quickly and safely as possible $[39,40]$. These cases highlight the importance of keeping a high level of suspicion for malignancy when working up musculoskeletal tumors and adhering to diagnostic and treatment algorithms.

When faced with these neoplasms, clinicians should not hesitate to repeat imaging studies such as MRI. Simply adding post-contrast sequences can greatly enhance the sensitivity and detail of these studies [22]. Maintaining a low threshold for consulting a musculoskeletal tumor specialist can also help avoid mismanagement of malignant neoplasms and potentially catastrophic complications. This was shown by Mankin, et al. in 1982 and confirmed on follow-up in 1996 when examining management of malignant neoplasms [38]. They showed $19 \%$ of patients for whom a biopsy error forced the surgeon to carry out a different or more invasive procedure or to use additional radiation or chemotherapy treatments. Ten percent of patients had a change in outcome including disability, loss of function, local recurrence, or death attributable to problems related to the biopsy, and 18 patients had an unnecessary amputation as a result of the biopsy. When comparing referring institutions to treatment centers they found significantly lower rates of biopsy related complications when these procedures were performed at treating institutions [38].

When faced with an intra-articular soft tissue mass, surgeons should take a stepwise approach to diagnosis 
as with any other musculoskeletal neoplasm. This begins with a thorough history and physical examination. Imaging studies should at minimum include plain radiography, and MRI (including T1 and T2, fat saturation, and post-gadolinium contrast series). Adjunctive $C T$ scan, PET scan, and ultrasound may be used in specific situations [41]. Following appropriate imaging studies some benign lesions may be routinely observed during follow up. Imaging studies yielding large differential diagnosis including potentially aggressive or malignant tumors is indication for biopsy. When performing a biopsy, the surgeon must operate as if the final pathology report will reveal malignancy. Biopsies are generally of 3 types: Needle biopsy; open incisional biopsy; or open excisional biopsy. Although there have been several publications illustrating successful excisional biopsy of intra-articular masses arthroscopically, the consensus of musculoskeletal oncologists is that arthroscopy is not indicated as a planned primary method of biopsy for an intra-articular soft tissue mass [42-46]. Insufflation of the knee with saline risks intra-articular spread of tumor cells and potential extravasation into the surrounding tissues $[11,22]$.

\section{Conclusion}

Diagnostic and management algorithms for the workup of soft tissue masses have been available and used effectively for many years. Though this is the case the fact that many malignant neoplasms appear benign on imaging studies, which leads to misdiagnosis and inappropriate treatment, necessitates that careful consideration of the differential diagnosis of isolated intra-articular mass lesions be undertaken. Treating physicians should have a low threshold in seeking consultation of a musculoskeletal oncologist to assist in the development of an appropriate differential diagnosis prior to proceeding with arthroscopic procedures.

It is important that orthopaedic surgeons recognize cases like the ones described above and continue to keep a high index of suspicion when dealing with new lesions of unknown etiology. By adhering to validated principals, surgeons can continue to appropriately diagnose and treat life-threatening disease, preventing complications and improving patient survival rates.

\section{References}

1. Sistla R, Tameem A, Vidyasagar JV (2010) Intra articular synovial sarcoma. Indian J Pathol Microbiol 53: 115-116.

2. Corey RM, Swett K, Ward WG (2014) Epidemiology and survivorship of soft tissue sarcomas in adults: A national cancer database report. Cancer Med 3: 1404-1415.

3. Sultan I, Rodriguez-Galindo C, Saab R, Yasir S, Casanova $\mathrm{M}$, et al. (2009) Comparing children and adults with synovial sarcoma in the Surveillance, Epidemiology, and End Results program, 1983 to 2005: An analysis of 1268 patients. Cancer 115: 3537-3547.

4. Weiss SW, Goldblum JR, Folpe AL (2007) Enzinger and Weiss's Soft Tissue Tumors. Elsevier Health Sciences.
5. Spillane AJ, A'Hern R, Judson IR, Fisher C, Thomas JM (2000) Synovial sarcoma: A clinicopathologic, staging, and prognostic assessment. J Clin Oncol 18: 3794-3803.

6. Helpert C, Davies AM, Evans N, Grimer RJ (2004) Differential diagnosis of tumours and tumour-like lesions of the infrapatellar (Hoffa's) fat pad: Pictorial review with an emphasis on MR imaging. Eur Radiol 14: 2337-2346.

7. Nordemar D, Öberg J, Brosjö O, Skorpil M (2015) Intra-articular synovial sarcomas: Incidence and differentiating features from localized pigmented villonodular synovitis. Sarcoma 2015: 903873.

8. Eilber FC, Dry SM (2008) Diagnosis and management of synovial sarcoma. J Surg Oncol 97: 314-320.

9. Gofman A, Issakov J, Kollender Y, Soyfer V, Dadia S, et al. (2007) Synovial sarcoma of the extremities and trunk: A long-lasting disease. Oncol Rep 18: 1577-1581.

10. Krieg AH, Hefti F, Speth BM, Jundt G, Guillou L, et al. (2011) Synovial sarcomas usually metastasize after $>5$ years: A multicenter retrospective analysis with minimum follow-up of 10 years for survivors. Ann Oncol 22: 458-467.

11. Friedman MV, Kyriakos M, Matava MJ, McDonald DJ, Jennings JW, et al. (2013) Intra-articular synovial sarcoma. Skeletal Radiol 42: 859-867.

12. Jo VY, Fletcher CD (2014) WHO classification of soft tissue tumours: An update based on the 2013. ( $4^{\text {th }}$ edn), Pathology 46: 95-104.

13. Park JH, Kang CH, Kim CH, Chae IJ, Park JH (2010) Highly malignant soft tissue sarcoma of the extremity with a delayed diagnosis. World J Surg Oncol 8: 84.

14. Choi ES, Han I, Cho HS, Kang HG, Kim JH, et al. (2015) Distinct clinical characteristics of unplanned excision in synovial sarcoma. Clin Orthop Surg 7: 254-260.

15. Ferrari A, Chi YY, De Salvo GL, Orbach D, Brennan B, et al. (2017) Surgery alone is sufficient therapy for children and adolescents with low-risk synovial sarcoma: A joint analysis from the European paediatric soft tissue sarcoma Study Group and the Children's Oncology Group. Eur J Cancer 78: $1-6$.

16. Brennan B, Stevens M, Kelsey A, Stiller CA (2010) Synovial sarcoma in childhood and adolescence: A retrospective series of 77 patients registered by the Children's Cancer and Leukaemia Group between 1991 and 2006. Pediatr Blood Cancer 55: 85-90.

17. Ferrari A, Gronchi A, Casanova M, Meazza C, Gandola L, et al. (2004) Synovial sarcoma: A retrospective analysis of 271 patients of all ages treated at a single institution. Cancer 101: 627-634.

18. Vlenterie $M$, Litière $S$, Rizzo $E$, Marréaud $S$, Judson I, et al. (2016) Outcome of chemotherapy in advanced synovial sarcoma patients: Review of 15 clinical trials from the European Organisation for Research and Treatment of Cancer Soft Tissue and Bone Sarcoma Group; Setting a new landmark for studies in this entity. Eur J Cancer 58: 62-72.

19. Ferrari A, Miceli R, Rey A, Oberlin O, Orbach D, et al. (2011) Non-metastatic unresected paediatric non-rhabdomyosarcoma soft tissue sarcomas: Results of a pooled analysis from United States and European groups. Eur J Cancer 47: 724-731.

20. Ferrari A, De Salvo GL, Brennan B, van Noesel MM, De Paoli A, et al. (2015) Synovial sarcoma in children and adolescents: The European Pediatric Soft Tissue Sarcoma Study Group prospective trial (EpSSG NRSTS 2005). Ann 
Oncol 26: 567-572.

21. Jones BC, Sundaram M, Kransdorf MJ (1993) Synovial sarcoma: MR imaging findings in 34 patients. AJR Am J Roentgenol 161: 827-830.

22. Morton MJ, Berquist TH, McLeod RA, Unni KK, Sim FH (1991) MR imaging of synovial sarcoma. AJR Am J Roentgenol 156: 337-340.

23. Murphey MD, Gibson MS, Jennings BT, Crespo-Rodriguez AM, Fanburg-Smith J, et al. (2006) From the archives of the AFIP: Imaging of synovial sarcoma with radiologic-pathologic correlation. Radiographics 26: 1543-1565.

24. Tateishi U, Hasegawa T, Beppu Y, Satake M, Moriyama N (2004) Synovial sarcoma of the soft tissues: Prognostic significance of imaging features. J Comput Assist Tomogr 28: $140-148$.

25. McLain R, Buckwalter J, Platz CE (1990) Synovial sarcoma of the knee: Missed diagnosis despite biopsy and arthroscopic synovectomy. A case report. J Bone Joint Surg Am 72: 1092-1094.

26. Fetsch J, Meis J (1992) Intra-articular Synovial Sarcoma. Laboratory Investigation.

27. McKinney CD, Mills SE, Fechner RE (1992) Intraarticular synovial sarcoma. Am J Surg Pathol 16: 1017-1020.

28. Scully SP, Temple HT, Harrelson JM (1999) Synovial sarcoma of the foot and ankle. Clin Orthop Relat Res 220-226.

29. Namba $Y$, Kawai A, Naito N, Morimoto $Y$, Hanakawa S, et al. (2002) Intraarticular synovial sarcoma confirmed by SYT-SSX fusion transcript. Clin Orthop Relat Res 221-226.

30. Ishida T, lijima T, Moriyama S, Nakamura C, Kitagawa T, et al. (1996) Intra-articular calcifying synovial sarcoma mimicking synovial chondromatosis. Skeletal Radiol 25: 766769 .

31. Kan JH, Hernanz-Schulman M, Damon BM, Yu C, Connolly SA (2008) MRI features of three paediatric intra-articular synovial lesions: A comparative study. Clin Radiol 63: 805812.

32. Bui-Mansfield LT, O'Brien SD (2008) Magnetic resonance appearance of intra-articular synovial sarcoma: Case reports and review of the literature. J Comput Assist Tomogr 32: 640-644.

33. Gresswell SD, Corsini AA, Balsamo LH, Miles EF (2013) Intra-articular synovial sarcoma treated with a transfemoral amputation: A case report and review of the literature. Mil Med 178: e956-e962.
34. Blacksin MF, Siegel JR, Benevenia J, Aisner SC (1997) Synovial sarcoma: Frequency of nonaggressive MR characteristics. J Comput Assist Tomogr 21: 785-789.

35. Abdelkrim SB, Trabelsi A, Hammedi F, Boudagga MZ, Bdioui A, et al. (2010) Synovial Sarcoma: A Clinicopathological and Radiological Study of 12 Cases Seen Over 18 Years. World J Oncol 1: 14-18.

36. Stacy GS, Nair L (2007) Magnetic resonance imaging features of extremity sarcomas of uncertain differentiation. Clin Radiol 62: 950-958.

37. Lewis JJ, Antonescu CR, Leung DH, Blumberg D, Healey $\mathrm{JH}$, et al. (2000) Synovial sarcoma: A multivariate analysis of prognostic factors in 112 patients with primary localized tumors of the extremity. J Clin Oncol 18: 2087-2094.

38. Mankin HJ, Mankin CJ, Simon MA (1996) The hazards of the biopsy, revisited. Members of the Musculoskeletal Tumor Society. J Bone Joint Surg Am 78: 656-663.

39. Han I, Kang HG, Kang SC, Choi JR, Kim HS (2011) Does delayed reexcision affect outcome after unplanned excision for soft tissue sarcoma? Clin Orthop Relat Res 469: 877883.

40. Fiore M, Casali PG, Miceli R, Mariani L, Bertulli R, et al. (2006) Prognostic effect of re-excision in adult soft tissue sarcoma of the extremity. Ann Surg Oncol 13: 110-117.

41. Mayerson JL, Scharschmidt TJ, Lewis VO, Morris CD (2014) Diagnosis and Management of Soft-tissue Masses. J Am Acad Orthop Surg 22: 742-750.

42. Nourissat G, Kakuda C, Dumontier C (2007) Arthroscopic excision of osteoid osteoma of the elbow. Arthroscopy 23: 799.e1-799.e4.

43. Sandokji A (2015) Arthroscopic treatment of an aneurysmal bone cyst of the patella: A case report. Int J Health Sci (Qassim) 9: 79-82.

44. Lu KH (2004) Subcutaneous pigmented villonodular synovitis caused by portal contamination during knee arthroscopy and open synovectomy. Arthroscopy 20: e9-e13.

45. Sharma V, Cheng EY (2009) Outcomes after excision of pigmented villonodular synovitis of the knee. Clin Orthop Relat Res 467: 2852-2858.

46. Colman MW, Ye J, Weiss KR, Goodman MA, McGough RL (2013) Does combined open and arthroscopic synovectomy for diffuse PVNS of the knee improve recurrence rates? Clin Orthop Relat Res 471: 883-890. 